\title{
Ludopedagogia: atendimento recreacional-pedagógico para pediatria do Hospital Universitário São Francisco de Paula - Pelotas/RS
}

\author{
Ludopedagogía servicio recreativo educacional para pediatría del \\ Hospital Universitário São Francisco de Paula - Pelotas/RS
}

\author{
${ }^{1}$ Nívia Celoí Barragan Ferreira; ${ }^{2}$ Daniel Moraes Botelho \\ ${ }^{1}$ niviamaia2012@hotmail.com, Universidade Católica de Pelotas; \\ 2daniel.botelho@ucpel.edu.br, Universidade Católica de Pelotas
}

\begin{abstract}
Resumo
O respectivo projeto procura apresentar o projeto de extensão universitária do Curso de Pedagogia da Universidade Católica de Pelotas, denominado "Ludopedagogia: atendimento recreacional-pedagógico para pediatria do Hospital Universitário São Francisco de Paula - Pelotas RS". A proposta apoia-se na perspectiva de que o brincar, no contexto da ludicidade infantil, é um fator relevante para estimular os processos de desenvolvimento humano, a fim de inserir a criança em momentos de descontração e promover habilidades cognitivas, bem como, amenizar as tensões provadas pelo ambiente hospitalar. A presença do brincar e tudo a ele relacionado é um dos fatores que facilitam e proporcionam a adaptação do enfermo ao ambiente hospitalar. Para tanto, é necessária a presença de um responsável (pedagogo) para mediar experiências lúdicas e criar um elo entre a magia do brincar e o ambiente familiar. Além da presença deste profissional a proposta visa a participação dos familiares para criar uma situação de bem estar e proporcionar a realização de trocas, desta maneira é possível amenizar a tensão emocional no ambiente hospitalar e promover estratégias para o desenvolvimento infantil.
\end{abstract}

Palavras-chaves: brincar, criança, hospital, lúdico.

\section{O brincar em unidades hospitalares: palavras iniciais}

A socialização entre as pessoas se faz necessário em todos os ambientes em que está inserida. Ela pode ser realizada de maneira verbal, gestual, escrita, desenhada, pintada, contada, dançada, enfim, por meio de diversas expressões e a principal de todas, para a criança, é o brincar. Neste sentido, o projeto de extensão universitária "Ludopedagogia: atendimento recreacional-pedagógico para pediatria do Hospital Universitário São Francisco de Paula" adota como princípio norteador a presença do brincar e do lúdico aliados ao viés pedagógico e aos diferentes elementos que auxiliam na adaptação do enfermo ao ambiente hospitalar. Para tanto, a presença de um profissional da área da educação tem a capacidade de realizar, além do apoio pedagógico, a mediação entre o infante e a realidade em que está inserido. Este processo busca qualificar as experiências lúdicas a fim de minimizar o estado de ansiedade por meio da descontração. Também, cabe salientar a necessária presença de familiares e objetos conhecidos, para com isso construir, neste ambiente hostil, uma experiência transitória positiva, essas estratégias promovem a resiliência e amenizam o sofrimento infantil no ambiente hospitalar.

O projeto de extensão procura elucidar sobre a relevante manutenção de espaços recreativos terapêuticos em unidades hospitalares pediátricas, como maneira de garantir aos pequenos 
enfermos, através do lúdico e do brincar, uma fonte de equilíbrio, distração, aprendizagem e socialização como maneira de promover o desenvolvimento integral da criança.

Conforme argumenta Novaes (2006) a saúde pediátrica envolve todos os aspectos globais do indivíduo, proporcionando momentos em que o brincar espontâneo ou orientado torna-se instrumento de aprendizagem que cumprirá objetivos que garantem não só o desenvolvimento psicossocial, mas físico e temporal, a presença de um técnico ou uma equipe capacitada torna-se fundamental para o processo de orientar e aperfeiçoar as atividades da forma mais lúdica e afetiva possível. Portanto, o lúdico, o brincar e as atividades que envolvem esse pequeno enfermo, aliviam seus medos e seus conflitos.

O brincar pertence exclusivamente ao imaginário infantil, neste mundo a criança apresenta resistência à presença de invasores. Neste sentido, o papel do cuidador, técnico, equipe capacitada e pedagogo, é fundamental no processo de orientar e construir um elo entre o espaço hospitalar e o mundo da fantasia, bem como, desta relação, extrair elementos de aprendizagem. Esta perspectiva está ancorada nos princípios do Estatuto da Criança e do Adolescente (ECA), um importante documento que visa assegurar e regularizar ações para a proteção da vida e da saúde da criança e do adolescente, conforme indicado no Art. $7^{\circ}$ do referido estatuto "a criança e o adolescente têm direito a proteção à vida e a saúde, mediante a efetivação de políticas sociais públicas que permitam o nascimento e o desenvolvimento sadio e harmonioso, em condições dignas de existência. (ECA, 2005)".

Diante disso, é possível evidenciar que toda a criança tem direito de ser assistida em todo o lugar: em sua casa, na escola, nos espaços de convívio social e/ou em qualquer dependência pública ou privada. Neste sentido, criar condições para amenizar o sofrimento e estimular o aprendizado da criança hospitalizada, também é um dever das instituições hospitalares. Para Novaes (2006, p. 110),

[...] para a criança doente, a importância do brincar no hospital encontra justificativa numa ampla gama de possibilidades, e serve-a em três diferentes funções: recreativa, educacional e terapêutica. Recreativa no momento em que concede prazer, diversão; terapêutica quando favorece a continuação de seu desenvolvimento neuromotor, social, emocional; e a vertente educacional quando contempla os aspectos intelectuais e cognitivos.

Reitera-se que o lúdico, o brincar e o incremento de atividades criativas, potencializa na criança o desenvolvimento de habilidades para aliviar seus medos e conflitos, bem como, os processos de aprendizagem, a fim de contribuir com o enfrentamento dos eventos da enfermidade e hospitalização. Portanto, as atividades desenvolvidas pelo projeto representam, aos envolvidos - acadêmicos, enfermos e acompanhantes - estratégias de recuperação terapêutica por meio de metodologias recreativas e pedagógicas para atender os objetivos de bem estar, autoestima, promoção da linguagem oral, escrita e corporal das crianças internadas na unidade pediátrica.

\section{Os caminhos percorridos: metodologias do projeto de extensão universitária}

Levando em consideração o ambiente hospitalar e a frequência com que crianças são internadas e recebem alta, as atividades são desenvolvidas de acordo com o público alvo e a faixa etária. $\mathrm{O}$ processo de atendimento ocorre, inicialmente, com a visita nos quartos, a partir desta é realizada uma sondagem diagnóstica, a fim de estabelecer a melhor estratégia de atendimento, de acordo com a necessidade encontrada. Estas estratégias envolvem diversas atividades, tais como: colagem com papel colorido, desenho livre com tinta têmpera, brincadeira mediada com brinquedos e jogos pedagógicos, hora do conto, conversação, estímulos à leitura e escrita e apoio de reforço escolar. 
Nas propostas que envolvem o brincar como maneira de aliviar o estresse hospitalar procura-se estimular na criança o acesso ao universo da imaginação, explorando a sua potencialidade criativa, as habilidades motoras finas e o raciocínio lógico com jogos de encaixe, quebracabeças. As atividades com desenhos e utilização de massa de modelar são expostas em painéis no corredor de acesso a sala de recreação terapêutica, como maneira de valorizar o fazer criativo da criança. Para aqueles recém-hospitalizados, seja pelas condições de saúde e/ou receio de utilização do espaço, o projeto disponibiliza kits de brinquedos e livros infantis para o uso no quarto de internação, os quais passam por processo de higienização na medida da sua devolução e utilização.

Para as atividades de apoio escolar, realizadas com crianças internadas por um período longo, faz-se necessário que levemos em conta a faixa etária e o seguimento escolar. Nesse processo é fundamental orientar e construir um elo entre o espaço hospitalar, a escola e o mundo da fantasia, pertencente exclusivamente à criança, um processo de mediação não só do processo de aprendizagem, mas entre os diferentes contextos.

Também, cabe salientar que o processo educativo e lúdico estende-se aos responsáveis pelas crianças enfermas, procura-se com isso esclarecer a relevância do processo de lúdico para a faixa etária em que a criança se encontra. Potencializar os laços afetivos, bem como extrair conteúdos que possam servir para as equipes de apoio psicológico da unidade pediátrica do referido hospital.

\section{Considerações finais: reflexões sobre as atividades extensionistas desenvolvidas}

O projeto encontra-se na sua fase inicial, o qual começou a ser realizado em setembro de 2015, neste sentido, que as considerações e reflexões ainda são incipientes dada a abrangência de situações vivenciadas em um ambiente hospitalar, principalmente para um estudante de pedagogia. Porém, considera-se que os resultados têm apresentado êxito na medida em que se percebe a maior adesão das crianças e seus familiares ao espaço recreacional, bem como os relatos da equipe pediátrica sobre o projeto. Com relação ao papel pedagógico do projeto, identifica-se ser este relevante na medida em que contribui para que as crianças em idade escolar recebam auxílio para a manutenção do vínculo com a escola, seja com as atividades de apoio, realização de deveres escolares ou mesmo pela mediação provocada no ato de brincar. Diante das vivências e reflexões que o projeto suscita, destaca-se que os momentos lúdicos, próprios do universo infantil, são capazes de estimular habilidades para o desenvolvimento integral e humanizado das crianças. Assim, evidencia-se a importância do projeto como estratégia articuladora para aproximação e formação de pedagogos na área hospitalar. Tendo em vista que esta proposta tem a oportunidade de inserir o estagiário como observador/ protagonista/mediador no ambiente hospitalar, possibilitando compartilhar vivências e reflexões com outros profissionais, em especial da área da saúde. Por fim, percebe-se que os projetos de extensão universitária assumem um papel relevante na formação acadêmica, tanto por beneficiar a atendimento as populações em vulnerabilidade, quanto ser uma possibilidade de construir novos conhecimentos a partir das trocas com acadêmicos e profissionais de outras áreas de formação, as quais geram análises e estimula a revisão de ambas as práticas, bem como, discussões e avaliações sobre os rumos do projeto.

\section{Referências}

BRASIL. Estatuto da Criança e do Adolescente. Senado Federal. Secretaria Especial de Editoração e Publicações. Subsecretaria de Edições Técnicas. 6. ed. Brasília, 2005. 
NOVAES. Luiza Helena Vinholes Siqueira; Brincar e Aprender: quem quer saber? O brincar como instrumento pedagógico no hospital. Pelotas: EDUCAT, 2006. 